\title{
La noción de "variación ciega" en el ámbito del cambio científico: una defensa
}

\author{
PATRICIA KING \\ Departamento de Filosofía \\ Universidad Autónoma del Estado de Morelos \\ pking@att.net.mx
}

\begin{abstract}
Resumen: La epistemología evolucionista considera que es posible dar cuenta del cambio conceptual en la ciencia mediante un modelo de explicación similar al modelo darwiniano de la evolución biológica. Tradicionalmente éste se elabora sobre la base de tres principios: variación ciega, transmisión y selección. Una de las principales objeciones a que se enfrenta esta corriente epistemológica es que la analogía no se sostiene dada la ausencia de intencionalidad de cualquier tipo en los procesos de evolución biológica (variación ciega) y la presencia de la intencionalidad humana en los procesos del cambio conceptual en la ciencia. Se suele responder postulando que hay procesos humanos no intencionales en conexión con este tipo de cambio. En este artículo se ofrece una defensa de la noción de "variación ciega conceptual" que, mediante la elaboración de una caracterización clara, pretende mostrar que su uso en el ámbito del cambio en la ciencia no requiere postular procesos no intencionales para dar cuenta del cambio conceptual.
\end{abstract}

Palabras clave: mutación conceptual, recombinación conceptual, replicación conceptual, modularidad conceptual

\begin{abstract}
Evolutionary epistemology considers that it is possible to account for conceptual change in science by means of a model of explanation similar to the Darwinian model of biological evolution. The last one has been traditionally built upon three principles: blind variation, transmission and selection. A central objection to this epistemological trend is that biological and epistemic development are not analogous because of the absence of any type of intentionality in biological evolution (blind variation), contrasting the presence of human intentionality in conceptual change due to science. A usual response is to postulate non intentional human processes in connection to this type of change. In this paper I offer a defense of the notion of "conceptual blind variation" by means of a clear characterization which, I consider, can be used within the scope of science and accounts for conceptual change, without the need to postulate any non intentional human processes.
\end{abstract}

Key words: conceptual mutation, conceptual recombination, conceptual replication, conceptual modularity

En las últimas décadas, la epistemología evolucionista ha sido acogida con entusiasmo en el medio de la teoría del conocimiento y de la filosofía de la ciencia como una manera interesante de dar cuenta del cambio científico. En el marco de la epistemología contemporánea, destacan dos corrientes evolucionistas frecuentemente (pero no necesariamente) articuladas entre sí. Michael Bradie las ha denominado "programa de evolución de mecanismos cognitivos" (Bradie 1997, p. 245), que concierne a una aplicación literal de la teoría de la evolución biológica para explicar los cambios que 
dieron lugar a las capacidades cognoscitivas específicas de la especie humana, ${ }^{1}$ y "programa de evolución de teorías", consistente en la elaboración de diversos patrones de explicación del cambio conceptual haciendo una analogía con diferentes patrones de explicación de la teoría de la evolución biológica. ${ }^{2}$ En este artículo situaremos nuestra defensa de la noción de "variación ciega" sólo en el marco de esta última corriente. Argumentaremos que existe una manera interesante de caracterizar la noción de variación ciega en el ámbito de lo conceptual, análoga a la noción de variación ciega que se usa en la biología evolucionista y que nos permitirá afirmar que, en un sentido sustancial, puede haber variación ciega en el ámbito científico, algo que muchos teóricos han puesto en duda.

Una de las principales objeciones a que se enfrenta esta corriente epistemológica es la afirmación de que la analogía no se sostiene porque la variabilidad biológica es aleatoria respecto de las necesidades de adecuación de los organismos a su medio ambiente, mientras que la variabilidad conceptual no lo es en relación con las necesidades teóricas de los científicos frente a un medio ambiente que de antemano se les presenta como problemático. A esta objeción la llamaremos objeción antievolucionista del cambio conceptual. ${ }^{3}$

La objeción es importante porque una de las aportaciones fundamentales de El origen de las especies de Darwin fue hacer ver que la variación fisiológica, anatómica y de comportamiento entre los organismos de una misma especie no depende de las necesidades de adaptación del organismo a su medio ambiente, tesis que obtiene su fundamentación genética en la moderna teoría sintética de la evolución. Esta tesis despojó a la noción de "variación" del halo de misterio que la envolvía en la época de Darwin, cuando la mayoría de los naturalistas consideraban que las variaciones en los organismos respondían de alguna manera a un fin adaptativo.

La trascendencia de esta aportación de Darwin a la ciencia es lo que ha inducido a muchos autores a sostener que, si la analogía entre la evolución biológica y el cambio conceptual ha de ser viable, entonces el epistemólogo evolucionista debe poder explicar en qué sentido se puede decir legítimamente que el cambio conceptual o teórico involucra un elemento de variación "ciega", pero si no da una respuesta satisfactoria a esta pregunta, más le valdría abandonar su empresa.

Varios autores han argumentado de diferentes maneras la pertinencia de la noción de variación ciega aplicada al cambio conceptual (por ejemplo,

\footnotetext{
${ }^{1}$ Autores como Lorenz (1977) y Ruse (1995), entre otros, han sostenido ese programa.

${ }^{2}$ Ese programa ha sido sustentado por autores como Rescher (1977) y Hull (1988), entre otros. Cabe aclarar que Popper (1984) y Campbell (1997) han defendido ambos programas.

${ }^{3}$ La objeción antievolucionista del cambio conceptual ha sido sostenida por autores como Simon (1969), Skagestad (1978) y Thagard (1997), entre otros.
} 
Campbell 1960, pp. 392-395, y 1997, pp. 54-56 y 67-68; Stein y Lipton 1990, pp. 42-46). Para Donald T. Campbell, como bien lo ha notado Peter Skagestad (1978, p. 612), una de las formas que adopta esta noción es la de un proceso inconsciente de variación y selección que redunda en la elaboración de hipótesis científicas nuevas (Campbell 1997, p. 56). La noción de variación ciega de Campbell, aplicable tanto a lo biológico como a lo conceptual, requiere: 1) que las variaciones ciegas sean independientes de las condiciones ambientales en el momento de su ocurrencia; 2) que, en cierto sentido, la ocurrencia de cada ensayo no esté correlacionada con la solución pertinente, y 3) el rechazo a la idea de que una variación que sigue a un ensayo incorrecto sea una corrección de ese ensayo previo (Campbell 1997, p. 55). Esta manera de entender la variación ciega se ha convertido en blanco de la crítica antievolucionista del cambio conceptual, porque apelar a procesos inconscientes de producción de hipótesis contraviene la idea ampliamente aceptada de que la producción de hipótesis no es un proceso aleatorio dada la importancia de los factores intencionales que involucra.

La estrategia de David Hull en contra de la objeción que nos ocupa consiste en cuestionar la distinción tajante entre "intencional" y "no intencional" (Hull 1988, pp. 468-474, y Hull 1997, pp. 131-132). Señala que casi todas las mutaciones genéticas ocurren al azar, pero algunas no. En algunos casos la intervención de lo intencional desempeña un papel importante en la evolución biológica, a saber, en aquellos en los que las mutaciones son inducidas a propósito por los biólogos en el laboratorio. Al respecto Hull dice: "Una parte de la selección basada en genes es intencional, la mayor parte no lo es. Según esta clasificación, la selección natural y la artificial son básicamente el mismo tipo de fenómeno" (Hull 1997, p. 132).

A diferencia de Hull, mi propuesta no cuestiona la distinción entre intencional y no intencional. En contraposición a Campbell, argüiré a favor de una caracterización de la noción de variación ciega conceptual que no requiere postular procesos inconscientes o no intencionales de producción de hipótesis nuevas para legitimar la pertinencia de dicha noción aplicada a lo conceptual.

La estrategia que voy a seguir es la siguiente. Primero precisaré la objeción antievolucionista del cambio conceptual. Luego pasaré a caracterizar la noción de variación ciega tanto para el ámbito de lo biológico como en conexión con el ámbito de lo científico. Incluiré argumentos para concluir que, tomando en cuenta dichas caracterizaciones, la analogía entre la evolución biológica y el cambio conceptual no es vulnerable a la objeción en cuestión. Finalmente, ofreceré un ejemplo que, de acuerdo con lo discutido, muestra un caso de variación ciega en el ámbito de la ciencia. 


\section{La objeción antievolucionista del cambio conceptual}

Comencemos preguntando qué se entiende por "variación ciega" en el contexto del cambio científico. En ocasiones esta noción se entiende como "no intencional". Con esta perspectiva, el antievolucionista argumenta que una variación conceptual no puede ser "ciega" porque es el resultado de un proceso deliberativo de búsqueda de solución a un problema que se le presenta al teórico. Aquí, la objeción consiste en sostener que las variaciones conceptuales están íntimamente conectadas a procesos inferenciales o prudenciales de búsqueda de solución a un determinado problema teórico, mientras que en el ámbito de la evolución biológica las variaciones no surgen como resultado de un proceso intencional de búsqueda, y por ello son consideradas ciegas. Entendida así, la objeción antievolucionista del cambio conceptual afirmaría que las hipótesis o teorías no se generan "ciegamente" con respecto a determinados problemas que el medio ambiente impone a los científicos (entendiendo "ciego" de esta manera), mientras que las variaciones fisiológicas, anatómicas o conductuales ocurridas en individuos de una población determinada sí se generan ciegamente con respecto a las presiones que un medio ambiente pertinente impone a los organismos.

Si bien esta objeción se refiere a la intencionalidad, no se trata aquí de una intencionalidad trascendente, como aquella a la que alude el conocido argumento del diseño, que sostiene que el orden de cosas existente sólo se explica, en última instancia, por la existencia de algún dios que lo planeó (por ejemplo, Lyell, quien consideraba que sólo una posición teológica de este tipo podría explicar la adaptación de las especies a su medio ambiente). Tampoco se trata de una intencionalidad inmanente a los organismos que conforman las distintas especies (un tipo de intencionalidad similar a aquel al que apela Lamarck en su teoría). ${ }^{4}$ Se trata, específicamente, de la intencionalidad humana, un tipo de intencionalidad cuya existencia es difícil de negar. Así, según esta objeción, las variaciones conceptuales están correlacionadas con algún problema específico, en el sentido en que las hipótesis surgen de manera deliberada como resultado de una intención; ¿cuál intención?, la intención de dar una respuesta aceptable al problema que viene al caso. Entonces, planteada así la objeción, tiene que ver con el supuesto de la intervención de la intencionalidad humana en el contexto del cambio científico y la ausencia de intervención de tal intencionalidad en el contexto de la evolución biológica. Por ejemplo, Michael Bradie dice:

Hay quienes podrían argumentar que el asunto realmente crucial es que las variaciones biológicas aparecen espontáneamente y al azar con respecto a las necesidades de los organismos, mientras que las conjeturas o teorías, aunque

\footnotetext{
${ }^{4}$ Para abundar sobre estos temas, véase Martínez 1997, cap. 7.
} 
pueden ser ciegas con respecto a su éxito potencial, no se generan azarosamente con respecto a las necesidades de quienes conocen, sino que se desarrollan como respuesta a un ambiente problemático. (Bradie 1997, p. 268)

Que las variaciones en el ámbito científico pueden ser ciegas con respecto a su "éxito potencial" es, en efecto, poco controversial. Kai Hahlweg argumenta en esta dirección cuando dice que "puede considerarse que las mutaciones ocurren al azar sólo respecto de los eventuales beneficios o daños que pueden ocasionar en el organismo en el cual tienen lugar" (Hahlweg 1989, pp. 64-65), y no en el sentido de que no estén sujetas a leyes físicas, por ejemplo, a leyes aplicables a nivel molecular. Esto es ampliamente reconocido por los científicos. Hahlweg sugiere que, análogamente, "los científicos razonan de manera lógica o teleológica" (ibid.); sin embargo, sus hipótesis también pueden considerarse azarosas con respecto a la estructura actual del mundo, porque es parte de esta estructura lo que los científicos buscan develar, pero no pueden saber de antemano si sus hipótesis serán exitosas o no. Y concluye: "el éxito o el fracaso eventual de una novedad conceptual no toma en cuenta (i.e., es azarosa respecto de) las intenciones humanas, sino que sólo depende de la naturaleza del mundo" (ibid.).

Esta conclusión no es problemática; el problema parece presentarse cuando se objeta, como lo hace Bradie, que las variaciones biológicas se generan o aparecen al azar con respecto a las necesidades de los organismos, mientras que las hipótesis no se generan o aparecen azarosamente en relación con las necesidades (o intenciones) de quienes conocen.

Esta vertiente de la objeción requiere un mayor desarrollo y precisión ulterior. Por un lado, no está claro qué debemos entender cuando en este contexto se dice que $X$ se genera o aparece (o no se genera ni aparece) al azar con respecto a $Y$. Por otro lado, la noción de variación ciega que podría derivarse de la objeción así planteada suscita ciertas dudas: ¿deberíamos pensar que si $X$ se genera o aparece al azar con respecto a $Y$, entonces $X$ es "ciega" respecto de $Y$, mientras que si $X$ no se genera o no aparece al azar respecto de $Y$, entonces $X$ no es "ciega" respecto de $Y$ ? ¿Por qué? ¿Será porque en el primer caso $X$ no depende de $Y$, mientras que en el segundo caso sí? Pero, ¿en qué sentido de "independencia"?

En lo que sigue trataré de elaborar, primero para el ámbito de lo biológico y después para el ámbito de lo científico, una noción de "independencia" que nos permita caracterizar el concepto de variación ciega de una manera clara. Una vez hecho esto, argumentaré que en el ámbito de la ciencia hay variaciones conceptuales que, ciertamente, son resultado de deliberaciones, pero que muy bien se pueden llamar "ciegas" porque en un sentido importante el conocimiento previo no determina (ni causal ni 
lógicamente) que esas variaciones sean la solución buscada por uno o más científicos a un problema determinado.

\section{La noción de variación ciega en el ámbito de lo biológico}

Los principales agentes de variación en individuos de la misma especie son las mutaciones y la recombinación genéticas. Por mutación genética, según el biólogo Jay Savage, se entiende "cualquier cambio en la organización química del gene" (Savage 1979, p. 69), y por recombinación "la creación de nuevos genotipos a partir de otros preexistentes" (Savage 1979, p. 74). La mutación genética es la fuente básica de variación, mientras que la recombinación, que sólo tiene lugar en el medio de la reproducción sexual, opera diseminando los mutantes en la población y desarrollando nuevas combinaciones o mezclas genéticas con material de genotipos previos. Así, el agente principal de la variación azarosa o "ciega" es la mutación y, en este contexto, por "azar", según Savage, debe entenderse lo siguiente: "La mutación es al azar, ya que la naturaleza del estímulo ambiental, que activa el cambio químico, no determina el lugar o sentido de cambio de la mutación" (Savage 1979, p. 69).

Desde esta perspectiva es conveniente caracterizar la noción de variación ciega en biología en función de la independencia de su valor adaptativo con respecto al agente causal del cambio:

(1) Una variación es ciega sólo si es causalmente independiente de los factores que determinan si es o no es una adaptación ambiental del organismo pertinente.

Se ha descubierto que entre algunas de las causas de variación en el ámbito de lo biológico se encuentran los rayos $\mathrm{X}$, los rayos cósmicos, los rayos ultravioleta, los rayos gama y la temperatura, entre otras (Savage 1979, p. 69). En este ámbito, encontramos un ejemplo de variación ciega en unos experimentos sobre la herencia llevados a cabo con la pequeña mosca de la fruta, Drosophila melanogaster. En estos estudios se mostró que un aumento en la temperatura causa un incremento en los coeficientes de mutación de esta especie de mosca. Según Savage, las mutaciones ocurrían en muchos genes, pero "no necesariamente en aquellos que controlan la tolerancia a la temperatura o adaptación de la mosca" (Savage 1979, p. 69).

En muchos casos las mutaciones no tienen valor adaptativo alguno; en otros, los menos, sí lo tienen. Si entre las mutaciones ocurridas en la pequeña mosca de la fruta a causa del aumento de temperatura consideramos las que no tienen nada que ver con una mayor tolerancia a ésta, estaremos frente a un caso de variación ciega causalmente independiente de la adap- 
tación o no de la mosca de la fruta en conexión con el aumento de su tolerancia a la temperatura. Asimismo, estaremos ante un caso de variación ciega en que las variaciones producidas son causalmente independientes de las condiciones ambientales de temperatura que constituyen un problema adaptativo para la población en cuestión. Pasemos ahora a precisar la noción de variación ciega en conexión con el desarrollo en la ciencia.

\section{La noción de variación ciega en el ámbito de lo científico}

Desde una perspectiva evolucionista, los principales agentes de variación de los elementos sustantivos de la ciencia son, en analogía con el cambio genético, las mutaciones y la recombinación conceptual. Por mutación conceptual en una ciencia (como la biología o la física) o en un área determinada de alguna ciencia (como la genética, la paleontología, la sistemática, etc.) entenderemos cualquier cambio en la estructura de un replicador correspondiente a esa ciencia o área de la ciencia. Un replicador, de acuerdo con la noción acuñada por David Hull, es una "entidad que transmite su estructura en gran parte intacta a través de replicaciones sucesivas" (Hull 1997, p. 118). Adoptaremos esta caracterización. Como ejemplos de replicadores en el ámbito de la ciencia pueden mencionarse las teorías, las creencias, los términos científicos y los patrones de explicación, entre otros. Por recombinación conceptual vamos a entender la "fertilización" conceptual por combinación de cierta información proveniente de distintas ciencias o áreas científicas en un momento determinado; por ejemplo, la combinación de ciertas ideas correspondientes a la economía política con ciertas ideas propias de la biología en un momento determinado. ${ }^{5}$

Las mutaciones y recombinaciones conceptuales tienen lugar mediante un tipo de procesos de tanteo similares a los que Campbell llama casos de ensayo y error. Estos procesos frecuentemente dan por resultado lo que identificaremos como "variaciones ciegas" de hipótesis (que son el tipo de variación conceptual que aquí nos ocupa). A continuación diferenciaremos dos factores que nos permitirán elaborar una caracterización más precisa de esta noción en el ámbito de la ciencia:

(a) una hipótesis $H$ correspondiente al cuerpo teórico $T$ es una variación ciega respecto de un problema pertinente $P$ sólo si $T$ no implica (lógicamente) que $H$ es una solución a $P$;

(b) una hipótesis $H$ correspondiente a un cuerpo teórico $T$ es una variación ciega respecto de un problema pertinente $P$ sólo si $T$ no ofrece razones para la ocurrencia de $H$ como una solución a $P$;

\footnotetext{
${ }^{5}$ La noción de "fertilización cruzada de disciplinas" es un término usual en psicología cognitiva. Nuestra caracterización de "combinación conceptual" es una variación simplificada de dicha noción.
} 
donde por "cuerpo teórico" entenderemos cierto conjunto de teorías establecidas y aceptadas por determinada comunidad de científicos y que es considerado por ellos como el conjunto de conocimientos adquiridos hasta el momento en su correspondiente área científica.

Usando las dos condiciones anteriores podemos ahora caracterizar la noción en cuestión.

(VCC) Una hipótesis $H$ correspondiente a un cuerpo teórico $T$ es una $v a$ riación ciega respecto de un problema pertinente $P$ sii (a) $T$ no implica que $H$ es una solución de $P$ y (b) $T$ no es razón para la ocurrencia de $H$ como una solución de $P$.

Desde esta perspectiva, una variación ciega corresponde a una variación nueva (o novedosa) en el sentido en que su ocurrencia no está apoyada ni implicada por el conocimiento previo adquirido y aceptado en su área científica de adscripción. Por ejemplo, es posible que en el proceso de tanteo, consistente en la producción de múltiples variantes hipotéticas correspondientes a la búsqueda de un científico por encontrar una solución aceptable al problema que trata de resolver, este científico mezcle creencias injustificadas o ajenas a su disciplina, o bien eche mano de intuiciones o prejuicios no apoyados en razones o evidencia alguna. Y, sin embargo, puede ser - y de hecho lo ha sido en muchas ocasiones- que alguna de las variantes producidas mediante este proceso de tanteo, es decir, alguna de las variantes cuya ocurrencia no está apoyada en el conocimiento previo, circunscrito hasta entonces a su área de adscripción, logre presentar ciertas características prometedoras que, según su creador, la hagan calificar como candidata a solución del problema pertinente. En este caso, estaríamos hablando de la generación de una variación ciega prometedora. Así, (VCC) implica que una variación ciega es aquella para cuya ocurrencia no hay razones ni teóricas ni empíricas provenientes del cuerpo teórico al que corresponde (más adelante regresaremos sobre este punto).

Desde luego, para dar cuenta de la evolución biológica o del cambio científico no basta con la noción de variación ciega. Por ejemplo, en el ámbito de lo biológico es inconcebible que a causa de una mutación (o de un conjunto de mutaciones ocurridas simultáneamente) le crezca una oreja humana a un mosquito. Para que una o más mutaciones hayan podido dar por resultado una oreja humana se requirieron un conjunto de restricciones generales en la posibilidad del cambio. Richard Lewontin sugiere que estas restricciones tienen que ver con el rango de mutaciones que pueden ocurrir a partir de genes dados (Lewontin 1998, p. 117). Sobre este mismo tema, Theodosius Dobzhansky dice: 
Un sistema biológico novel puede surgir por evolución sólo si el material genético bruto para su construcción está disponible para la selección natural. Al menos alguno de los bloques genéticos de construcción con los cuales el nuevo sistema ha de ser construido, debe ser más viejo que el sistema mismo. (Dobzhansky et al. 1977, p. 451)

Esto quiere decir que sólo a partir de la existencia de determinada dotación genética pueden ocurrir ciertas mutaciones y otras no. Esto es así porque una mutación es justamente un cambio en la organización química de determinado gen, lo cual significa que si no hay tal gen, no hay tal cambio. Desde luego, se presupone que la dotación de genes dados sobre los cuales pueden operarse las mutaciones ha sido, asimismo, producida por variación ciega y selección.

De manera similar, para dar cuenta del cambio científico no basta con la noción de variación ciega conceptual, se requiere algo más. ${ }^{6}$ En analogía con el ámbito de lo biológico, las restricciones pertinentes en el ámbito de lo científico tienen que ver con el rango de mutaciones que pueden presentarse a partir de un conjunto de replicadores dados. Esto quiere decir que sólo a partir de cierto acervo conceptual dado, correspondiente a un cuerpo teórico $T$, pueden ocurrir algunas mutaciones que den lugar a ciertas variaciones ciegas conceptuales y no a otras. El cambio científico por variación y selección es históricamente contingente, pero el material disponible sobre el cual suceden las variaciones sujetas a selección es, en sí mismo, uno de los determinantes del cambio que se puede producir. En este sentido podemos decir que un cuerpo teórico $T$ actúa como restricción del rango de variaciones conceptuales posibles en su área científica de adscripción. Así, en la generación de hipótesis nuevas, al menos parte de la materia prima sobre la cual se producen las mutaciones que dan lugar a las variaciones ciegas conceptuales consiste en un cuerpo (o partes de un cuerpo) teórico pertinente ya establecido y aceptado por cierta comunidad de científicos y que es considerado por ellos mismos como el conjunto de conocimientos ya adquiridos en su correspondiente área científica; pero, como dice Campbell, "más allá de la aplicación de lo ya conocido, los nuevos descubrimientos deben ser producidos por una generación de alternativas ciegas" (Campbell 1997, p. 68). Esto quiere decir que una vez que el conocimiento previo ha hecho su trabajo determinando el campo de posibles variaciones, éstas han de producirse ciegamente mediante un proceso de tanteo, de ensayo y error. En el ámbito de lo científico, de manera similar al ámbito de lo

\footnotetext{
${ }^{6}$ Por ejemplo, para Campbell, este "más" tiene que ver con su noción de jerarquía anillada de procesos vicariantes, es decir, de procesos sustitutivos del medio ambiente natural (Campbell 1997, pp. 51-56), mientras que para Stein y Lipton se relaciona con su noción de "heurísticas de descubrimiento", un tipo de heurísticas usualmente generadas mediante procesos ciegos de ensayo y error y que guían en parte la producción de hipótesis nuevas (Stein y Lipton 1989, p. 40).
} 
biológico, se presupone que la dotación de replicadores que constituyen un cuerpo teórico establecido y aceptado en un momento determinado ha sido generada por variación ciega y selección, ya que en su momento constituyó conocimiento nuevo.

Por otro lado, desde el punto de vista aquí expresado, la producción de alternativas ciegas no tiene nada de irracional (contra lo que suele pensarse). Por ejemplo, si llegamos al convencimiento de que cierta anomalía existente en un momento dado no es explicable mediante los patrones de explicación vigentes, ${ }^{7}$ lo sensato es pensar que no es la anomalía la que está fuera de lugar, sino que es el cuerpo teórico al que corresponden tales patrones de explicación el que es inapropiado para explicarla; de aquí que la crítica a dicho cuerpo teórico (o a partes de él) sea en este sentido lo más razonable. Esta manera de pensar involucra ir más allá de lo ya sabido. En el terreno del descubrimiento, uno no debe estar interesado primeramente en las razones que justifican nuestras variantes hipotéticas, sino en los efectos que éstas pudieran tener en la búsqueda de una posible solución del problema en el que se trabaja; la justificación (de haberla) vendrá después. Esta manera de pensar, acompañada de una táctica por ensayo y error, es algo que puede llegar a romper con los viejos patrones de explicación en favor de otros inéditos, lo que abre así la posibilidad de producir una mutación conceptual "de largo alcance", es decir, una teoría nueva que pueda dar lugar a la proliferación de una familia de teorías emparentadas entre sí, como fue el caso de la teoría de Darwin, que dio lugar a la corriente teórica que comúnmente llamamos darwinismo.

Ahora bien, con respecto a las variaciones por recombinación conceptual (que caracterizamos al principio de este apartado), requerimos introducir cierta terminología. Para este propósito nos va a ser muy útil la noción de "sistema modular". Para Hull, un sistema conceptual tiene un tipo de estructura "modular" cuando se presenta como una variedad de subsistemas conceptuales o módulos de conceptos (y relaciones entre conceptos) que son susceptibles de cambiar a lo largo del tiempo y que gozan de relativa autonomía entre sí, pero también de relativa permeabilidad al flujo de información entre ellos, sin que ninguno de éstos sea más central que otro (Hull 1988, p. 493). Este autor sugiere que se consideren los sistemas modulares en dos niveles: el nivel de los sistemas de creencias de científicos individuales y el nivel de lo que hemos venido llamando cuerpos

\footnotetext{
${ }^{7}$ Por "patrón de explicación" adoptaremos la caracterización de Sergio Martínez, quien dice que: "A grandes rasgos, un patrón de explicación consiste en una determinada manera de explicar algo científicamente. Cada patrón de explicación incorpora ciertas nociones interconectadas de causalidad y ley de la naturaleza, adopta una manera de concebir la relación entre el todo y las partes, y acepta ciertas reglas acerca del alcance y del tipo de inferencias que podemos hacer a partir de la experiencia" (Martínez 1997, p. 19).
} 
teóricos o, como los denomina él, sistemas conceptuales compartidos por una comunidad científica mediante el uso de terminología similar.

Para entender esta idea de modularidad, veamos primero el nivel individual. Hull propone, con referencia a la noción de "modularidad individual", que el sistema de creencias (o sistema conceptual individual) de cualquier persona y, por ende, de cualquier científico, sea pensado como un sistema dinámico que va variando con el tiempo. Pero, además, para Hull este sistema en ningún momento se presenta como un sistema homogéneo (en el sentido de totalmente coherente) ni en el tiempo ni en el espacio, sino más bien como un mosaico, es decir como un sistema taraceado de zonas conceptuales coherentes pero parcialmente independientes entre sí (Hull 1988, pp. 493-496). Para describir un sistema conceptual individual, Hull usa la metáfora de los retazos de tela cosidos a modo de un edredón: "Aun cuando hay áreas de sistematicidad en el sistema conceptual de cualquier científico, sólo algunos científicos tienen éxito en formar visiones del mundo totalmente sin costuras. Las áreas son parcialmente dependientes, parcialmente independientes" (Hull 1988, p. 493). Esto quiere decir que el sistema conceptual de un científico particular no siempre es totalmente coherente, sino que puede presentar áreas en conflicto.

Por otro lado, su idea de modularidad aplicada a sistemas conceptuales compartidos - - , en nuestra terminología, a cuerpos teóricos-, consiste asimismo en una red conceptual taraceada, con zonas de conceptos y de relaciones entre conceptos parcialmente independientes entre sí. En este sentido, sugiere que, sobre todo al inicio de una investigación, dos científicos que comparten un mismo sistema conceptual nunca pueden estar en total acuerdo, que incluso pueden diferir acerca de cuáles son los principios generales de la teoría que trabajan en común. ${ }^{8}$ Y no sólo al principio, también en proyectos de investigación ya avanzados se presenta bastante heterogeneidad conceptual. Por ejemplo, refiriéndose a las polémicas de principios del siglo xx en torno a cuán graduales o cuán abruptos son los cambios referidos a la especiación biológica, justo cuando muchos consideraban que el cambio gradual era un principio de la teoría de Darwin, dice:

Gould (1977, p. 24) argumenta que Darwin estaba equivocado al pensar que el gradualismo era esencial a su teoría y que Goldschmidt estaba igualmente equivocado al pensar que su teoría de monstruos esperanzadores era no darwinista. "Porque Goldschmidt no hizo caso a las advertencias de Huxley de que la esencia del darwinismo — el control de la evolución por selección naturalno requiere la creencia del cambio gradual." Si el gradualismo no es esencial al

\footnotetext{
${ }^{8}$ Hull 1988, p. 493. Para la evidencia que respalda estas ideas de Hull, como para el uso que le da a su noción de "principios generales" (es decir, aquellos principios que caracterizan una determinada teoría), véase su capítulo 6, en particular las pp. 230-231.
} 
darwinismo, entonces ni el punto de vista puntuacionista de Eldredge y Gould (1972) ni el punto de vista saltacionista de Goldschmidt (1940) son no darwinistas o antidarwinistas. Andrew Huxley (1981, p. ii) está de acuerdo. El puntuacionismo versus saltacionismo es meramente un "debate dentro de la red darwinista" [...]. Cuando se trata de la función de las mutaciones neutrales, Gould piensa que sus puntos de vista son originales y antidarwinistas. Stebbins y Ayala (1981, p. 967) no están de acuerdo. Sin importar qué papel desempeñen las mutaciones neutrales en la evolución, la teoría resultante debe contar como darwinista. (Hull 1988, p. 202)

Ésta es una muestra de cómo aquellos científicos que sostienen un mismo sistema conceptual compartido o un mismo cuerpo teórico, lo que realmente comparten es un sistema conceptual modular, ya que pueden diferir en muchos aspectos, incluso respecto de los principios generales de dicho sistema. Es probable que los científicos involucrados no consideren que están compartiendo un mismo sistema conceptual, pero, como se muestra en el caso citado, también es posible que esta creencia sea una mera confusión debida a la modularidad del sistema.

Ahora bien, hay que señalar que Hull reconoce que, conforme el tiempo pasa y la selección hace su trabajo, la modularidad de un sistema conceptual compartido puede llegar a estabilizarse por un periodo indefinido (Hull 1988, p. 136). Esto quiere decir que, conforme el tiempo pasa y la selección hace su trabajo, aquello que configura los principios generales y los postulados relevantes de un determinado cuerpo teórico puede llegar a ser de consenso, sin que se elimine la posibilidad de que, pasando el tiempo, se inicie otro periodo de desacuerdos.

Tomando en cuenta la idea de modularidad conceptual (individual y compartida), se puede dar un sentido a la idea de cómo es posible producir variaciones ciegas por mutación o por recombinación (entendidas como se caracterizaron al inicio de este apartado). Si entendemos el sistema de creencias de un científico particular como sistema adquirido mediante un proceso de interacción de esta persona con el mundo (natural y social) que la rodea, y lo consideramos como un sistema modular, tiene sentido la idea de que tal científico pueda producir un conjunto de variaciones ciegas al proceder por ensayo y error mezclando de manera ingeniosa creencias provenientes de diferentes módulos conceptuales, creencias injustificadas o ajenas a su disciplina, o echando mano con perspicacia de intuiciones o prejuicios no apoyados en razones. Con este método de tanteo, restringido de la manera antes indicada por el cuerpo teórico de adscripción pertinente y puesto en marcha de manera audaz, es probable que muchas de las variantes producidas así resulten meros errores, pero también que algunas de ellas logren calificar como variaciones prometedoras. 
A partir de las caracterizaciones ofrecidas en este apartado, estamos ahora en condiciones de establecer la analogía entre variación ciega en el campo de lo biológico y variación ciega en el ámbito de lo científico.

Las variaciones ciegas en el ámbito de lo conceptual (en el sentido de VCC) son, en cuanto tales, similares de manera relevante a las variaciones ciegas en el ámbito de lo biológico, porque ocurren lógica y racionalmente independientes de los cuerpos teóricos vigentes y de los factores ambientales que en última instancia determinan si son o no adecuadas empíricamente. Asimismo, son por completo independientes de los requerimientos o deseos del científico en conexión con la replicación y proliferación de sus hipótesis, de forma similar a como las segundas son causalmente independientes de los factores que determinan si es o no una adaptación ambiental pertinente y, además, son del todo independientes de las necesidades del organismo en conexión con su sobrevivencia y reproducción, que, de ser satisfechas, redundarían en la replicación y proliferación de su material genético.

Resumiendo: el cambio conceptual en la ciencia involucra dos tipos de explicación complementarios: por un lado, el de las variaciones ciegas conceptuales, por el otro, el de las restricciones conceptuales debidas a un acervo de replicadores apropiado, dado como materia prima sobre la cual pueden tener lugar las variaciones. Una variación ciega conceptual es aquella para cuya ocurrencia lo ya conocido y aceptado por la comunidad científica pertinente no ofrece razón alguna; la ocurrencia de variaciones ciegas es contingente, pero el rango de sus ocurrencias está restringido por el conocimiento establecido y reconocido por una comunidad científica pertinente. Una variación ciega conceptual puede llegar a ser un descubrimiento novel o una hipótesis nueva o novedosa, pero no hay garantía alguna para ello. Muy por el contrario, muchas variaciones ciegas generadas mediante el mismo proceso de tanteo por un mismo científico (o científicos) son incorrectas y se extinguen inmediata o mediatamente. Nótese que algunas variaciones pueden ser errores detectados de manera inmediata por su productor, otras pueden durar algunos segundos, horas o días hasta ser descartadas, y otras más pueden perdurar hasta la etapa de selección comúnmente llevada a cabo mediante experimentación o presentación de evidencia suficiente para su aceptación por la comunidad; al llegar a ser contrastadas empíricamente, algunas salen exitosas de dichas pruebas, otras no.

Finalmente, cabe señalar que si se restringe la idea del cambio en la ciencia a las teorías nuevas que hacen cambiar el estado general de cosas en la ciencia - como lo han hecho las teorías elaboradas por Newton, Darwin y Einstein, entre otras-, entonces se le resta sustancia y fuerza a una epistemología de corte evolucionista. Un evolucionismo epistemológico interesante es aquel que señala que muchos cambios en la ciencia, incluyendo 
cambios graduales, es decir cambios relativamente pequeños (no revolucionarios pero de alguna manera novedosos), sí son cambios evolutivos, en el sentido de que se generan mediante variaciones ciegas sujetas a presiones de selección y replicación. Nuestra noción de variación ciega VCC permitiría afirmar algo así. Para aclarar esta idea, a continuación veremos un ejemplo de lo que, desde nuestra perspectiva, podemos llamar un cambio gradual en la ciencia.

\section{Un ejemplo de variación ciega conceptual en el ámbito de lo científico}

Un caso estudiado por Steve Woolgar (1991) permite apreciar la generación de algunas variaciones ciegas en conexión con el cambio gradual en la ciencia. Se trata del descubrimiento de los pulsares. Este descubrimiento tuvo lugar dentro del grupo de radioastronomía de Cambridge en el que participaban, entre otros investigadores, los doctores A. Hewish, S.J. Bell, J.D.H. Pilkington, P.F. Scott y R.A. Collins, y se hizo público en 1968 a través del artículo "Observation of a Rapidly Pulsating Source" como publicación conjunta de estos investigadores (Hewish et al., 1968).

Un atardecer de 1967, un miembro de dicho grupo de radioastronomía se encontraba operando el radiotelescopio cuando apareció en el receptor lo que él consideró una emisión irregular, algo que, a la luz de su experiencia y sus creencias, registró como "trazo anómalo" (con este nombre se registraban perturbaciones pasajeras en la observación debidas al polvo en los instrumentos, nubes pasajeras y aun pájaros entrometidos, nada de importancia). Sin embargo, lejos de desaparecer, comenzó a observarse dicho trazo una y otra vez. Para Hewish y Bell (miembros del grupo en cuestión), la reiterada aparición del trazo comenzó a tomar la forma de una anomalía expresada mediante la proposición "es un trazo anómalo", algo incompatible con sus experiencias y el cuerpo teórico que compartían del cual formaba parte, digamos, el estado de la astrofísica y la radioastronomía imperantes en aquel entonces. Esto los motivó a investigar más a fondo dicho fenómeno y a raíz de estas investigaciones surgió el primer conjunto de variaciones ciegas conceptuales.

El uso de registros de alta velocidad en la investigación mostró una regularidad pulsante del objeto observado. A partir de esta información, comenzaron a plantearse varias hipótesis. Como veremos, es posible calificar de ciegas algunas de ellas en la medida en que ninguna de las teorías vigentes hasta ese momento proporcionaba razones para su ocurrencia, ni, por lo demás, permitía explicar dicho fenómeno. La primera hipótesis no exitosa pretendió resolver el misterio de la anomalía arguyendo que se debía a la explosión de algún objeto celeste que estaba causando una actividad temporal de radio, un tipo de fenómeno considerado por todos como normal. Frente a esta hipótesis y en contraposición a ella surgieron 
otras. Por ejemplo, un investigador sostuvo que el carácter pulsante del objeto dejaba claro que no podía tratarse de un estallido de ese tipo, sino que muy probablemente era una mera interferencia de tipo inusual. A estas alturas, más miembros del grupo de Cambridge se habían incorporado tanto a la investigación como a la polémica en torno a las controvertidas hipótesis que había acerca de la naturaleza de tan misterioso fenómeno. Más tarde surgió una famosa hipótesis de cuya ceguera no puede haber duda alguna: que "las señales representaban comunicaciones de otra civilización inteligente" (Woolgar 1991, p. 95). La idea de que se estaba a punto de establecer contacto con civilizaciones extraterrestres fue tomada muy en serio por algunos investigadores, quienes denominaron a las cuatro fuentes pulsantes descubiertas hasta entonces LGM1, LGM2, LGM3 y LGM4, iniciales que se referían a Little Green Men.

Antes de aquel histórico atardecer de 1967, la mayoría de las fuentes de radio eran identificadas como provenientes de objetos gaseosos, difusos y extensos, que podían ser los restos de supernovas e incluso galaxias enteras. Pero los objetos recién descubiertos no sólo emitían señales intermitentes, sino que, además, no eran ni difusos ni extensos, sino puntuales. La mejor variación hipotética, que vino a derrotar a las propuestas anteriores, consistió en admitir que se había descubierto un nuevo tipo de objeto celeste que emitía ondas de radio de manera intermitente y regular al que se le dio el nombre de pulsar. La aceptación de esta solución por parte del grupo de Cambridge se manifestó con la publicación conjunta de "Observation of a Rapidly Pulsating Source" que ya hemos mencionado antes.

Cuando los resultados obtenidos por el grupo de Cambridge se dieron a conocer en el medio de varios grupos de investigación pertinentes, no se hicieron esperar las variantes hipotéticas acerca de la naturaleza del pulsar. Científicos pertenecientes a diferentes grupos propusieron sucesivamente que dicho fenómeno correspondía a "una estrella enana blanca", "una estrella de neutrones con un satélite", "la interacción plásmica entre estrellas binarias de neutrones"; y la lista continuó hasta que la selección por contrastación empírica ${ }^{9}$ logró el consenso en torno a la solución que perdura hasta nuestros días: "estrellas de neutrones en rotación, que [emiten] pulsos de ondas de radio debido a una complicada interacción entre sus campos magnéticos y la materia de su alrededor" (Hawking 1988, p. 130).

Este ejemplo muestra que deben considerarse como productos de la evolución conceptual no sólo los grandes cambios que revolucionan a la ciencia en poco tiempo (como la teoría de Darwin o la de Einstein), sino también muchas otras transformaciones graduales que la hacen avanzar poco a poco, todos esos cambios relativamente pequeños pero nuevos o

\footnotetext{
${ }^{9}$ Consideraremos que una teoría está bien contrastada en un momento dado cuando tenga observaciones, evidencia empírica (directa o indirecta) o resultados experimentales que cuenten en ese momento como buenas razones de corte empírico para adoptarla.
} 
novedosos que expanden y desarrollan los cuerpos teóricos de la ciencia. Desde esta perspectiva es razonable pensar que es el trabajo minucioso de miles y miles de científicos el que va construyendo la red de conocimientos básicos que sirve de materia prima a los grandes logros revolucionarios.

\section{Conclusión}

En este trabajo he argumentado en contra de la objeción antievolucionista de lo conceptual. Según ella, la analogía entre la evolución biológica y la epistémica no se sostiene porque la variación conceptual involucra procesos intencionales, mientras que la variación biológica es ciega en este sentido. En respuesta a esta objeción he propuesto una caracterización de la noción de variación ciega conceptual VCC en términos de no implicación y falta de apoyo de una hipótesis nueva $H$ por parte del cuerpo teórico $T$ al que $H$ corresponde. Esta caracterización no requiere postular procesos inconscientes o no intencionales para contar como un ingrediente apropiado en la explicación del cambio en la ciencia. He argumentado que, para hacer uso adecuado de la noción de variación VCC en una explicación aceptable de este tipo, se requiere complementarla con la idea de sistema modular de tipo hulliano (tal y como se presentó en la sección 3), idea que permite explicar en qué sentido toda variación ciega conceptual (toda hipótesis nueva) correspondiente a un cuerpo teórico $T$ está restringida por $T$, de manera similar a como la dotación genética correspondiente a una especie biológica restringe toda variación ciega biológica que pueda ocurrir en los organismos pertenecientes a esa especie biológica. Esto me permite concluir que la objeción antievolucionista de lo conceptual falla, porque es posible elaborar una noción de variación ciega conceptual que no requiere apelar a procesos inconscientes o no intencionales para que, en combinación con otros elementos explicativos, pueda ser operativa en una explicación plausible del cambio en la ciencia.

Las ideas presentadas en este trabajo abren la posibilidad de pensar, en el marco mismo de la evolución de teorías, en la producción de hipótesis nuevas por ensayo y error como un proceso de pensamiento creativo donde el ingenio y la perspicacia humanas se ponen en juego combinando y recombinando experiencias e ideas de los distintos módulos conceptuales correspondientes a sistemas de creencias compartidos o personales. Esto no debe sorprender si se piensa que el proceso de descubrimiento e invención es una práctica milenaria que debe echar mano de la materia prima a su alcance para combinar y recombinar viejas ideas con el propósito de adecuarlas a los requerimientos de su medio ambiente (natural y social) procediendo, sí, sobre la base de lo ya sabido, pero avanzando de aquí ya sin más guía que su habilidad para transformar viejas estructuras conceptuales y combinar viejas ideas de manera productiva. 


\section{BIBLIOGRAFÍA}

Bradie, M., 1997, "Una evaluación de la epistemología evolucionista”, en Martínez y Olivé 1997, pp. 243-284.

Campbell, D.T., 1997, "Epistemología evolucionista", en Martínez y Olivé 1997, pp. 43-103.

— 1960, "Blind Variation and Selective Retention in Creative Thought as in Other Knowledge Processes", Psychological Review, vol. 67, pp. 380-400.

Dobzhansky, T., F. Ayala, G.L. Stebbins y J.W. Valentine, 1977, Evolution, W.H. Freeman, San Francisco, California.

Eldredge, N. y S.J. Gould, 1972, "Punctuated Equilibria: An Alternative to Phyletic Gradualism", en T.J.M. Schopf (comp.), Models in Paleobiology, Freeman, Cooper and Co., San Francisco, pp. 82-115.

Goldschimdt, R., 1940, The Material Basis of Evolution, Yale University Press, New Haven.

Gould, S.J, 1977, "The Return of Hopeful Monsters", Natural History, vol. 86, pp. 20-24.

Hahlweg, K., 1989, "A Systems View of Evolution and Evolutionary Epistemology", en Hahlweg y C.A. Hooker (comps.), Issues in Evolutionary Epistemology, State University of New York Press, NuevaYork, pp. 45-78.

Hawking, S.W., 1988, Historia del tiempo, Editorial Crítica, Grijalbo, México.

Hewish, A., S.J. Bell, J.D.H. Pilkington, P.F. Scott y R.A. Collins, 1968, "Observation of a Rapidly Pulsating Source", Nature, vol. 217, pp. 709-713.

Hull, D., 1997, "Un mecanismo y su metafísica: una aproximación evolucionista al desarrollo social y conceptual de la ciencia”, en Martínez y Olivé 1997, pp. 105145.

— 1988 , Science as a Process. An Evolutionary Account of the Social and Conceptual Development of Science, The University of Chicago Press, Chicago/Londres.

Huxley, A., 1981, "Anniversary Address of the President", Suplemento de Royal Society News, vol. 12, pp. i-vii.

Lewontin, R., 1998, “The Evolution of Cognition: Questions We Will Never Answer", en D. Scarborough y S. Stemberg (comps.), An Invitation to Cognitive Science. Methods, Models, and Conceptual Issues, vol. 4, The MIT Press, Cambridge, Mass., pp. 107-132.

Lorenz, Konrad, 1977, Behind the Mirror, Methuen, Londres.

Martínez, S., 1997, De los efectos a las causas. Sobre la historia de los patrones de explicación científica, Paidós/Instituto de Investigaciones Filosóficas-UNAM, México.

Martínez, Sergio y León Olivé (comps.), 1997, Epistemología evolucionista, Paidós/Instituto de Investigaciones Filosóficas-unAM, México.

Popper, K., 1984, "Evolutionary Epistemology", en J.W. Pollard (comp.), Evolutionary Theory: Paths into the Future, John Wiley and Sons, Londres.

Rescher, N., 1977, Methodological Pragmatism, Basil Blackwell, Oxford.

Richards, R.J., 1997, "El modelo de selección natural y otros modelos en la historiografía de la ciencia”, en Martínez y Olivé 1997, pp. 147-183.

Ruse, M., 1995, Evolutionary Naturalism, Routledge, Londres/NuevaYork.

Savage, J., 1979, Evolución, Compañía Editorial Continental, México. 
Simon, H., 1969, The Sciences of the Artificial, The MIT Press, Cambridge, Mass.

Skagestad, P., 1978, "Taking Evolution Seriously: Critical Comments on D.T. Campbell's Evolutionary Epistemology", Monist, vol. 61, pp. 611-621.

Stebbins, G.L. y F. Ayala, 1981, "Is a New Evolutionary Synthesis Necessary?", Science, vol. 213, pp. 967-971.

Stein E. y Lipton, P., 1989, "Where Guesses Come From: Evolutionary Epistemology and the Anomaly of Guided Variation", Biology and Philosophy, no. 4, pp. 33-56.

Thagard, P., 1997, "En contra de la epistemología evolucionista", en Martínez y Olivé 1997, pp. 285-295.

Tulmin, S., 1972, Human Understanding, Oxford University Press, Oxford.

Woolgar, S., 1991, Ciencia: abriendo la caja negra, Anthropos, Barcelona.

Recibido el 4 de febrero de 2004; aceptado el 28 de septiembre de 2004. 